Document downloaded from:

http://hdl.handle.net/10251/50898

This paper must be cited as:

Medina Folgado, JR.; Molines Llodra, J.; Gómez Martín, ME. (2014). Influence of armour porosity on the hydraulic stability of cube armour layers. Ocean Engineering. 88:289-297. doi:10.1016/j.oceaneng.2014.06.012.

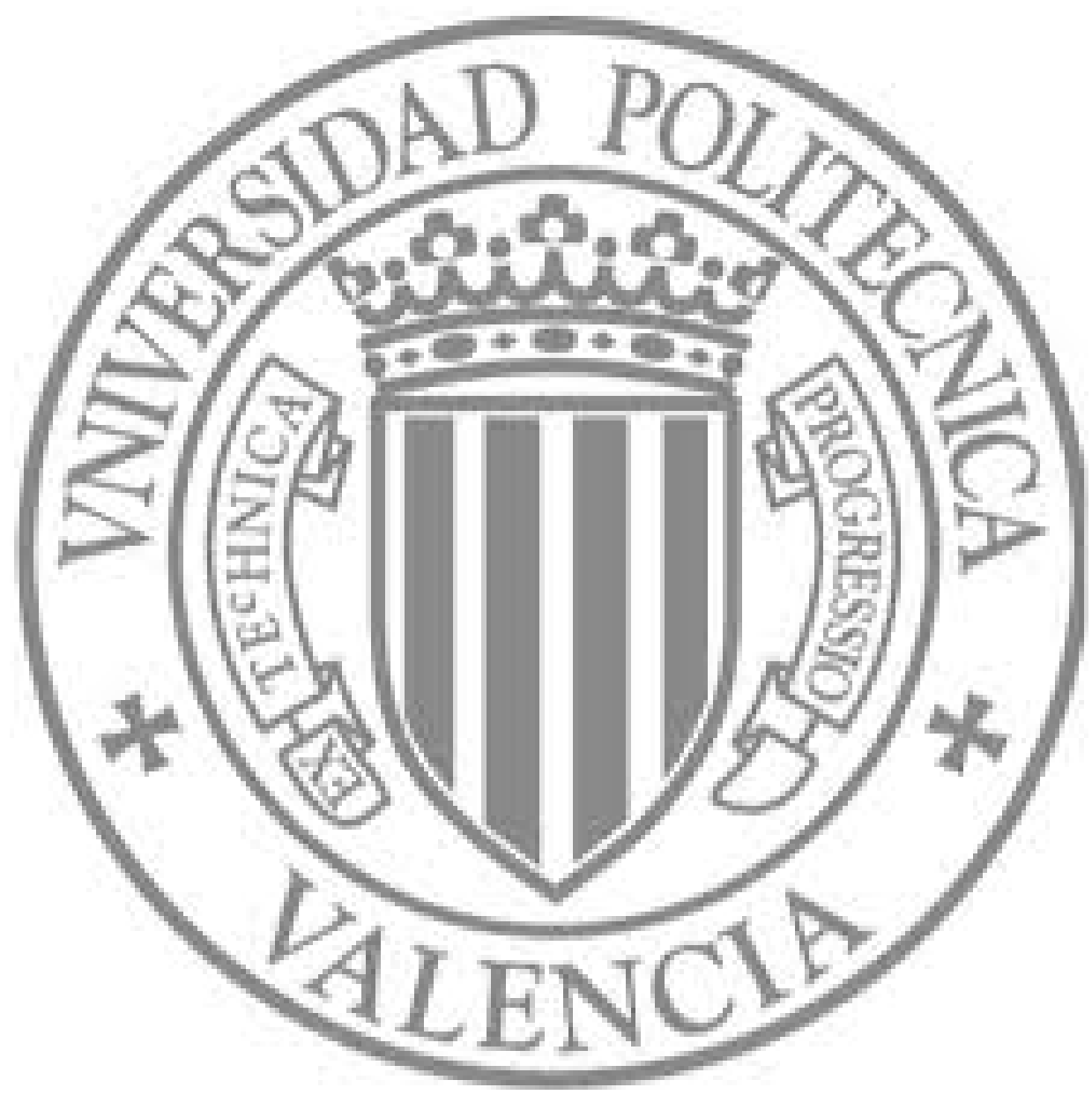

The final publication is available at

http://dx.doi.org/10.1016/j.oceaneng.2014.06.012

Copyright Elsevier 


\title{
Influence of Armour Porosity on the Hydraulic Stability of Cube Armour Layers
}

Josep R. Medina ${ }^{1}$, Jorge Molines ${ }^{2}$, and M. Esther Gómez-Martín ${ }^{3}$

${ }^{1}$ Professor and ${ }^{2}$ Asst. Res., Dept. of Transportation, ETSI Caminos, Universitat Politècnica de València, Camino de Vera s/n, 46022 Valencia, Spain. Tel.: +34 963877370; Fax: +34 963877379.jrmedina@upv.es (corresponding author), jormollo@upvnet.upv.es

${ }^{3}$ Asst. Prof., Dept. of Civil Engineering, Escuela Politécnica Superior, Universidad de Alicante, San Vicent del Raspeig s/n, 03690 Alicante, Spain. Tel.: +34 965903707; Fax: +34 965903678. esther.gomez@ua.es

\begin{abstract}
Armour placement and packing density directly affect construction costs and hydraulic performance of mound breakwaters. In this paper, the literature concerning the influence of armour porosity on the hydraulic stability of single- and double-layer armours is discussed. Qualitative and quantitative estimations for the influence of armour porosity and packing density on the hydraulic stability are given for the most common concrete armour units. The analysis focuses on specific 2D hydraulic stability tests of double-layer cube armours with different armour porosities and permeable core. The packing density showed a 1.2-power relationship with the stability number for cube units. The literature review and experimental results with small-scale breakwater models protected with a variety of armour units clearly indicate that a significant increase in armour porosity above the recommended values substantially decreases armour hydraulic stability. To avoid uncontrolled model effects, packing density should be routinely measured in small-scale tests, and armour placement techniques should be monitored at prototype scale. The actual packing density obtained in small-scale models and prototypes has to be explicitly reported, because packing density significantly affects hydraulic stability during service time.
\end{abstract}

\section{Key words:}

Breakwater, Heterogeneous Packing, Armour porosity, Packing density, Armour damage, Hydraulic stability, Armour unit, Cubic block.

\section{Highlights:}

(1) Armour porosity affects the hydraulic stability of armour layers. 
(2) Armour porosity or packing density is rarely included in armour stability formulae.

(3) Packing density of randomly-placed double-layer cube armours is a relevant design factor affecting hydraulic stability and construction costs.

(4) A significant 1.2-power relationship has been found between the stability number and packing density for double-layer cube armours.

(5) The packing density of the armour layer has to be explicitly reported in small-scale tests and monitored at prototype scale.

\section{Introduction}

Rock armoured mound breakwaters have been built for centuries. When breakwaters had to be constructed in harsher environmental conditions, larger stones were needed for armour layers. In the $19^{\text {th }}$ century, when local quarries were not able to provide stones of the appropriate size and price, precast concrete cubes and parallelepiped blocks were introduced and numerous precast concrete armour units were designed later to optimize the armour layer of mound breakwaters. The overall breakwater construction cost depends on numerous factors, these being associated to design and logistic factors, including the type of armour material (unreinforced concrete, granite rock, sandstone rock, etc.), armour unit mass, personnel and material unit costs, total concrete consumption, placement equipment, casting, handling and stacking procedures, etc. This paper focuses on armour porosity and the associated packing density, because these two parameters significantly affect breakwater hydraulic performance, construction costs and payments.

Hudson's formula published in 1959, popularized later by USACE (1984), focused the attention of the engineering community on the stability coefficients $\left(\mathrm{K}_{\mathrm{D}}\right)$ associated with different armour units, randomly placed in double-layer armours with a prescribed nominal porosity, $\mathrm{P}$, and a layer coefficient, $\mathrm{k}_{\Delta}$. Using the equivalence $\mathrm{H}=\mathrm{H}_{\mathrm{s}}$ in the original Hudson formula, Eq. 1 is known as the generalized Hudson formula, still widely used by practitioners to compare different breakwater designs at the preliminary stage, including double- and single-layer armours,

$$
M=\frac{H_{s}^{3} \rho_{r}}{K_{D}\left[\frac{\rho_{r}}{\rho_{w}}-1\right]^{3} \cot \alpha}=\frac{H_{s}^{3} \rho_{r}}{\Delta^{3} K_{D} \cot \alpha}
$$

in which $K_{D}$ is the stability coefficient; $M$ is the armour unit mass; $H_{s}$ is the incident significant wave height; $\alpha$ is the slope angle: $\Delta=\left(\rho_{\mathrm{r}} / \rho_{\mathrm{w}}-1\right)$ is the relative submerged mass density; and $\rho_{\mathrm{r}}$ and 
$\rho_{\mathrm{w}}$ are the armour unit and water mass densities, respectively. The equivalent cube size or nominal diameter of the armour units is defined as $D_{n}=\left(M / \rho_{r}\right)^{1 / 3}$; and Eq. 1 can be re-written as a function of the stability number, $\mathrm{N}_{\mathrm{s}}=\mathrm{H}_{\mathrm{s}} /\left(\Delta \mathrm{D}_{\mathrm{n}}\right)=\left(\mathrm{K}_{\mathrm{D}} \cot \alpha\right)^{1 / 3}$.

If Eq. 1 is used to compare different armour units in similar storm conditions, the higher the $\mathrm{K}_{\mathrm{D}}$ is, the lower armour unit mass and concrete consumption. Since the invention of the Tetrapod in 1950, numerous armour units have been invented in the search for high values of $K_{D}$ and the corresponding economic savings. Usually, high values of $\mathrm{K}_{\mathrm{D}}$ are associated with complex armour unit shapes (e.g. Dolos), reducing concrete consumption and requiring smaller rocks in the filter layer and lighter placement cranes. These savings should exceed the additional costs associated with more expensive concrete and complex formworks, production, handling, stacking and placement compared to the simple and easy to handle conventional cubes and parallelepiped blocks.

The invention of Accropode ${ }^{\mathrm{TM}}$ in 1980 and other interlocking units later, designed for singlelayer armouring, significantly reduced concrete consumption and cost (see Vincent et al., 1989, and Holtzhausen, 1998). Structural integrity is a key issue when using these bulky units as are adequate placement and packing density to guarantee interlocking of units during service time (see Jensen, 2013, and Latham et al., 2013). In the preliminary design phase, armour porosity and placement technique are usually considered as secondary factors, which are either explicitly prescribed (see Mouquet, 2009, and Paulsen and Wareing, 2009) for single-layer armours or implicitly defined by engineering manuals (e.g. USACE, 1984, and CIRIA et al., 2007) for randomly-placed double-layer armours. There are other environmental and structural characteristics not included in Eq.1 which may also have a significant influence on the armour stability, such as packing density, Iribarren's number, core permeability and relative crestfreeboard; this paper focuses attention on packing density because it is frequently a key factor affecting construction cost, concrete consumption and breakwater safety.

At prototype scale, armour units are usually placed using crawler cranes; armour porosity and placement below mean water level (MWL) are not easy to control due to poor visibility, waves and wind (see Medina et al., 2010). Because armour porosity and packing density are not explicitly included in most of the hydraulic stability formulae used by practitioners, such as Eq. 1, short-term cost optimization tends to increase armour porosity of prototypes above tested and recommended values. Unfortunately, a significant increase in the armour porosity usually leads to a significant reduction in hydraulic stability. This paper analyses the influence of packing density on the hydraulic stability with special attention to double-layer cube armours. The aim is 
to estimate the model effect associated to armour porosity, which can differ substantially between the prototype and the corresponding small-scale model tested in laboratory.

Section 2 includes a literature review concerning the effects of armour porosity on the hydraulic stability of different armour units. Section 3 focuses on porosity changes within cube armours due to Heterogeneous Packing ( $\mathrm{HeP}$ ) and explains the virtual net method used to measure armour damage in the small-scale tests reported in this research. Section 4 describes the 2D hydraulic stability tests of cube models with different armour porosities carried out for this study including the analysis of the experimental results. Finally, the most relevant conclusions of this research are provided in Section 5.

\section{Literature on the influence of armour porosity on hydraulic stability}

Porosity is an intuitive general concept widely used to refer to the volume of voids in a granular system. Nevertheless, armour porosity is not always easy to determine; armour thickness must be defined first, which may be an easy task for orderly-placed armour units but not so straightforward for randomly-placed units. Armour thickness of randomly-placed units is usually referred to as $n=1$ (single-layer) or $n=2$ (double-layer) times the equivalent cube size, $\mathrm{nD}_{\mathrm{n}}=\mathrm{n}\left(\mathrm{M} / \rho_{\mathrm{r}}\right)^{1 / 3}$. However, most engineering manuals (e.g. USACE, 1984 and CIRIA, 2007) recommend, for each unit, a specific layer coefficient or layer thickness factor, $\mathrm{k}_{\Delta}$, and a specific nominal porosity, P, called "fictitious porosity" by Zwamborn (1978). Placing density ( $\varphi\left[\right.$ units $\left./ \mathrm{m}^{2}\right]$ ) is a real physical variable which is controlled by the placement grid and is related to $\mathrm{k}_{\Delta}$ and $\mathrm{P}$ according to

$$
\varphi=n\left(k_{\Delta}\right)(1-P)\left(\frac{\rho_{r}}{M}\right)^{2 / 3}
$$

in which $\mathrm{n}$ is the number of layers in the armour; $\mathrm{k}_{\Delta}$ is the layer coefficient; $\mathrm{P}$ is the nominal porosity; and $M / \rho_{r}=D_{n}{ }^{3}$ is the volume of the armour unit. Different pairs of $k_{\Delta}$ and $\mathrm{P}$ lead to the same placing density, $\varphi$; thus, Frens (2007) drew attention to misinterpretations caused by the use of different criteria regarding the layer coefficient and the porosity concept. In order to prevent misunderstandings, for randomly-placed armours, this paper refers to the number of layers $\mathrm{n}$, the packing density $\phi=\varphi \mathrm{D}_{\mathrm{n}}^{2}$, and armour porosity $\mathrm{p}=1-\phi / \mathrm{n}$, being the packing density a useful parameter to measure the relative consumption of concrete in the armour layer, which may be considered the dimensionless placing density:

$$
\phi=\varphi D_{n}^{2}=n\left(k_{\Delta}\right)(1-P)=n(1-p)
$$


in which $\varphi$ is the placing density; and $\mathrm{p}$ is the armour porosity parameter used in this research. Armour porosity $\mathrm{p}$ is equal to nominal porosity $\mathrm{P}$ only when considering a layer coefficient of $\mathrm{k}_{\Delta}=1.00$. Therefore, this study uses a two-parameter armour characterization (n and p or $\phi$ ), instead of the conventional three-parameter characterization (n, P and $\mathrm{k}_{\Delta}$ ). For instance, USACE (1984) recommended $\mathrm{n}=2, \mathrm{P}=50 \%$ and $\mathrm{k}_{\Delta}=1.04$ for double-layer Tetrapod armours, which is equivalent to $\mathrm{n}=2$ and $\mathrm{p}=48 \%$ or $\phi=1.04$. Using different notations for the same concepts, CIRIA (2007) recommended $\mathrm{n}=2, \mathrm{P}=50 \%$ and $\mathrm{k}_{\Delta}=1.02$ for Tetrapod armours which is equivalent to $\mathrm{n}=2$ and $\mathrm{p}=49 \%$ or $\phi=1.02$.

Armour porosity and placement can be very well controlled in small-scale tests; dry construction, perfect view of the armour layer and placement by hand are ideal laboratory construction conditions which do not exist at prototype scale. On the contrary, prototype conditions usually involve placement grids, crawler cranes, blind underwater placement and other restrictions that generate uncertain armour porosities and these may significantly change in space and time (see Medina et al., 2010, and Latham et al., 2013). In this paper, the literature review is focused on armour porosity and its influence on hydraulic stability. The analysis of the literature reveals that a significant reduction in the packing density $\phi$ below the recommended value results in a significant decrease in the hydraulic stability of the armour.

\subsection{Single- and double-layer rock armours}

Hald et al. (1998) carried out small-scale tests of single-layer rock armours with cot $\alpha=1.5$ and different placement techniques, which may be used to describe the hydraulic performance of hundreds of single-layer rock armours in rubble-mound breakwaters built in Norway since 1886. Armour porosity $\mathrm{p}=40 \%$ [ $\phi=0.60]$ was assumed to compare armour damage measured with profiles and visual counting techniques, and results were compared with conventional double-layer rock armours. Single-layer rock armours with orderly-placed rocks were more stable than double-layer rock armours with randomly-placed rocks, which were much more stable than single-layer rock armours with randomly-placed rocks. Vandenbosch et al. (2002) conducted small-scale tests of single-layer rock armours with slopes in the range $1.5 \leq \cot \alpha \leq 3.0$; different placing densities were obtained varying the layer thickness and placement techniques. Armour porosity $\mathrm{p}=30 \%(\phi=0.70)$ was considered "normal" and a decrease in packing density resulted in decreased armour stability. USACE (1984) 
recommended $\mathrm{p}=37 \%(\phi=1.26)$ for double-layer rough and smooth quarrystone armours; however, armour porosity is not easy to measure. Latham et al. (2002) provided a rapid survey method to estimate packing densities and analysed 23 real breakwaters with $30.0 \% \leq \mathrm{p} \leq 40.1 \%$ having an average porosity of rock armour $\mathrm{p}=34 \%(\phi=1.32)$.

The literature on rock armour described above clearly indicates that randomly-placed rock armours show higher hydraulic stability if packing density is higher. Double-layers are more stable than single-layer armours, and hydraulic stability decreases if armour porosity increases. On the other hand, the study by Hald et al. (1998) on Norwegian breakwaters proved that orderly-placed single-layer rock armours with high packing densities have higher hydraulic stabilities than conventional randomly-placed double-layer rock armours.

\subsection{Single- and double-layer Tetrapod armours}

Van der Meer (1999) analysed small-scale test results of randomly-placed single- and doublelayer Tetrapod armours corresponding to models having $\cot \alpha=1.5$ and a packing density $0.48 \leq \phi \leq 1.02$; for surging waves, the stability number was explicitly related to packing density according to:

$$
N_{s}=\frac{H_{s}}{\Delta D_{n}}=\left(3.75 \frac{N_{o d}^{0.5}}{N^{0.25}}+0.85\left(0.40+0.61\left[\frac{\phi}{\phi_{S P M}}\right]\right)\right) S_{o m}{ }^{-0.1}
$$

and the formula for plunging waves resulted in:

$$
N_{s}=\frac{H_{s}}{\Delta D_{n}}=\left(8.6 \frac{N_{o d}^{0.5}}{N^{0.25}}+3.94\left(0.40+0.61\left[\frac{\phi}{\phi_{S P M}}\right]\right)\right) S_{o m}{ }^{-0.1}
$$

in which $\mathrm{N}_{\mathrm{s}}$ is the stability number; $\mathrm{s}_{\mathrm{om}}=\mathrm{H}_{\mathrm{s}} /\left[\mathrm{gT}_{\mathrm{m}}{ }^{2} / 2 \pi\right]$ is the wave steepness using the mean period; $\mathrm{N}$ is the number of waves; $\phi$ is the packing density; $\phi_{\mathrm{SPM}}=1.04(\mathrm{n}=2$ and $\mathrm{p}=48 \%)$ is the recommended packing density given by USACE (1984); and $\mathrm{N}_{\mathrm{od}}$ is the relative damage level which may be comparable to half the dimensionless damage, S (see Van der Meer, 1999). Regardless the number of layers ( $n=1$ or 2 ), the higher the packing density of Tetrapod armours, the higher the hydraulic stability will be.

Vandenbosch et al. (2002) conducted small-scale tests of single-layer Tetrapod armours with slope $\cot \alpha=1.5$ and packing densities $\phi=0.78,0.73$ and 0.62, and later De Jong et al. (2004) tested similar single-layer Tetrapod models; these experimental results confirmed that higher packing densities generated higher hydraulic stability.

Gürer et al. (2005) carried out small-scale tests of double-layer Tetrapod armours, using two 
specific placement techniques, slope $\cot \alpha=1.5$ and packing density $\phi=0.94$ and 0.80 ; the placement technique with the higher porosity showed higher hydraulic stability for initial damage, but initial damage was followed by a rapid failure beyond a critical wave height.

Taking into account the literature reviewed herein, it is clear that single- and double-layer Tetrapod armours with randomly-placed units have higher hydraulic stability if packing density is higher; however, special placement techniques and armour patterns may also significantly influence specific failure functions.

\subsection{Single- and double-layer cube armours}

Van Gent et al. (1999) tested single-layer cube armours, randomly-placed, with slope $\cot \alpha=1.5$ and $\mathrm{p} \%=25 \%, 30 \%$ and $40 \%$ ( $\phi=0.75,0.70$ and 0.60 ); hydraulic stability increased when armour porosity decreased, being $\mathrm{p}=25 \%$ the most stable armour with significant faceto-face fitting arrangements after wave attack. Van Buchem (2009) carried out similar smallscale tests of single-layer cube armours, but placed by hand in ordered horizontal rows, with slopes $\cot \alpha=1.5$ and 2.0 and $\mathrm{p}=20 \%, 28 \%$ and 35\%; hydraulic stability was the highest for $\mathrm{p}=28 \%$ and decreased for $\mathrm{p}=20 \%$ and $\mathrm{p}=35 \%$.

Although basing his experiments only on Tetrapod units, Van der Meer (1999) postulated a similar function to estimate the influence of armour porosity on the hydraulic stability of cube armours; the explicit formula proposed for cube armour was:

$$
N_{s}=\frac{H_{s}}{\Delta D_{n}}=\left(6.7 \frac{N_{o d}^{0.4}}{N^{0.3}}+1.0\left(0.40+0.61\left[\frac{\phi}{\phi_{S P M}}\right]\right)\right) S_{\text {om }}^{-0.1}\left(1+0.17 \exp \left[-0.61\left(\frac{R_{c}}{D_{n}}\right)\right]\right)
$$

with the same notation used in Eqs. 4 and 5 but using $\phi_{\mathrm{SPM}}=1.17$ ( $\mathrm{n}=2$ and $\mathrm{p}=42 \%$ ); $\mathrm{R}_{\mathrm{c}}$ is the crest freeboard; and $D_{n}=\left(M / \rho_{r}\right)^{1 / 3}$ is the equivalent cube size or nominal diameter.

USACE (1984) and CIRIA (2007) recommended $p=42 \%$ for double-layer modified cube and cube armours with randomly-placed units. Vandenbosch et al. (2002) conducted small-scale tests of double-layer cube armours, also randomly-placed, but with slope $\cot \alpha=1.5$ and $\mathrm{p}=25 \%$, 30\% and 40\%; hydraulic stability was reported much higher for $\mathrm{p}=30 \%$ than $\mathrm{p}=40 \%$ but it decreased for $\mathrm{p}=25 \%$. Nonetheless, it should be considered that when crawler cranes are used and underwater viewing conditions are poor, it is not possible to randomly place cubes having $\mathrm{p} \leq 35 \%$ (see Medina et al., 2010). Therefore, double-layer randomly-placed cube armour has higher hydraulic stability if packing density is higher, although the placement technique at prototype scale may then be a critical issue for high packing density armours.

Yagci and Kapdasli (2003) carried out small-scale tests of double-layer Antifer cubes with a 
modified random technique called "irregular placement", $\cot \alpha=2.0$ and packing densities $\phi=0.94$ ( $\mathrm{p}=53 \%)$ and $\phi=1.13$ ( $\mathrm{p}=43.5 \%)$. Yagci et al. (2004) later tested double-layer Antifer cubes with "irregular placement", $1.25 \leq \cot \alpha \leq 2.5$ and packing densities $1.08 \leq \phi \leq 1.16$ (46\% $\geq \mathrm{p} \geq 42 \%$ ); the $\mathrm{K}_{\mathrm{D}}$ values obtained by both Yagci and Kapdasli (2003) and Yagci et al. (2004) were lower than common values given in the literature which are based on a higher recommended packing density $\phi=1.21$ ( $\mathrm{p}=39.5 \%$ ). After conducting 17 small-scale tests with double-layer Antifer cubes, $\cot \alpha=1.5$, different placement techniques and armour porosities $0.90 \leq \phi \leq 1.22(55 \% \geq \mathrm{p} \geq 39 \%)$, Frens (2007) found that higher $\phi$ for the same placement technique, resulted in higher hydraulic stability and high wave reflection, runup and overtopping rates.

Taking into account the experimental results of the three tests with different armour porosities and irregular placement reported by Frens (2007), it is clear that an increase of 7\% in packing density (from $\phi=1.14$ to $\phi=1.22$ ) resulted in a $20 \%$ increase in the stability number corresponding to $10 \%$ armour damage. Hydraulic stability of cubes and Antifer cubes clearly decreases when packing density decreases below the recommended values.

\subsection{Double-layer Dolos armours}

Carver and Davidson (1978) carried out small-scale tests with double-layer Dolos armours with randomly-placed units, using regular waves, $\cot \alpha=1.5$ and packing densities $0.63 \leq \phi \leq 0.83$ (68.5\% $\geq \mathrm{p} \geq 58.5 \%$ ); the armours with a lower packing density also had a lower hydraulic stability. Zwamborn (1978) conducted similar experiments with higher packing densities $0.83 \leq \phi \leq 1.15$ (58.5\% $\geq \mathrm{p} \geq 42.5 \%)$ finding little difference in damage. Zwamborn (1978) also recommended $\phi=1.00$ ( $\mathrm{p}=50 \%)$ for practical applications, while USACE (1984) recommended a significantly lower packing density $\phi=0.83$ ( $\mathrm{p}=58.5 \%)$.

Burcharth and Liu (1992) tested double-layer Dolos armours with slope $\cot \alpha=1.5$; based on these results and the observations of other authors, they proposed Eq. 7 with an explicit linear relationship between packing density and stability number:

$$
N_{s}=\frac{H_{s}}{\Delta D_{n}}=(47-72 r) D^{1 / 3} N^{-0.1} \phi
$$

in which $\mathrm{N}_{\mathrm{s}}$ is the stability number; $\mathrm{r}$ is the Dolos waist ratio; $\mathrm{D}$ is the relative number of displaced units; $\mathrm{N}$ is the number of waves; and $\phi$ is the packing density. For double-layer Dolos armours, if $\phi$ increases, the stability number increases. The Dolos armours showed a 
linear relationship between $\mathrm{N}_{\mathrm{s}}$ and $\phi$ in the range $0.61 \leq \phi \leq 1.00$.

\subsection{Single-layer Accropode ${ }^{\mathrm{TM}}$, Core-Loc ${ }^{\mathrm{TM}}$ and $\mathrm{Xbloc}^{\mathrm{R}}$ armours}

Several bulky and second-generation armour units (see Dupray and Roberts, 2009) have been designed to balance hydraulic stability and structural strength for single-layer armouring. Usually, armour unit placement is a critical issue and both prototype and small-scale models have to follow specific prescriptions. According to Van Gelderen and Auld (2009), Accropodes must be placed accurately in a predefined grid so as to obtain the required interlocking, while Paulsen and Wareing (2009) described in detail ten specific placement criteria to adequately place Core-Loc ${ }^{\mathrm{TM}}$ units with a real packing density $0.61 \leq \phi \leq 0.66$ (39.0\% $\geq \mathrm{p} \geq 34.0 \%$ ). When armour unit interlocking is significant (e.g. Accropode ${ }^{\mathrm{TM}}$, Core$\operatorname{Loc}^{\mathrm{TM}}$ and $\mathrm{Xbloc}^{\mathrm{R}}$ ), the Hudson formula is no longer valid and steeper slopes $(\cot \alpha=4 / 3)$ are recommended.

Vincent et al. (1989), Holtzhausen and Zwamborn (1991) and Burcharth et al. (1998) compared small-scale tests results of single-layer Accropode ${ }^{\mathrm{TM}}$ armours from different laboratories, and relevant discrepancies were found; single-layer Accropode $^{\mathrm{TM}}$ armour stability was proved to be highly sensitive to core permeability, while placements were stated to have been made 'as prescribed by patent-owner'. However, packing density prescriptions and recommended placement techniques have been changing over time following engineering experience and research advances. For instance, Melby and Turk (1994) recommended a packing density $\phi=0.54$ ( $\mathrm{p}=46.0 \%$ ) for Core-Loc ${ }^{\mathrm{TM}}$ armour (slope $\cot \alpha=4 / 3$ ), and CLI (2012) recently recommended design packing densities for Accropode ${ }^{\mathrm{TM}}$ and Core-Loc ${ }^{\mathrm{TM}}$ depending on the unit size ( $\phi \approx 0.65$ for the smallest units and $\phi \approx 0.62$ for the largest units).

Bakker et al. (2005) carried out 2D small-scale tests to analyse the influence of the packing density on the hydraulic stability of single-layer $\mathrm{Xbloc}^{\mathrm{R}}$ armours. A higher packing density, $0.57 \leq \phi \leq 0.60$ ( $43 \% \geq \mathrm{p} \geq 40 \%$ ), leads to a higher hydraulic stability; in this range, a $4 \%$ increase in packing density resulted roughly in a $12 \%$ increase in the stability number. Furthermore, models with the lowest packing density, $0.55 \leq \phi \leq 0.57 \quad(45 \% \geq \mathrm{p} \geq 43 \%$ ), showed relevant armour settlements. DMC (2011) recommended a design packing density $\phi=0.58$ ( $\mathrm{p}=42 \%)$ for $\mathrm{Xbloc}^{\mathrm{R}}$ armours because Bakker et al. (2005) observed that armours with $0.55 \leq \phi \leq 0.57$ settled to obtain $\phi \approx 0.58$.

Bulky armour units such as Accropode ${ }^{\mathrm{TM}}$, Core-Loc ${ }^{\mathrm{TM}}$ and $\mathrm{Xbloc}^{\mathrm{R}}$, placed in single-layer armours, must achieve specific armour porosity targets, depending on the geometry and size 
of the unit, and following specific placement criteria to obtain the appropriate interlocking. For these bulky armour units, it is well known that armour porosity and placement techniques have a significant influence on the hydraulic stability. Lower-than-recommended packing densities may lead to significant undesired armour settlements, poor interlocking and lower hydraulic stability.

\section{Cube armours and Heterogeneous Packing (HeP)}

Although not included in most stability formulae, armour porosity and the associated packing density are obviously relevant factors affecting the breakwater armour hydraulic performance as well as the construction cost. Armour porosity is not properly considered in some smallscale experiments; in numerous papers and reports, poor information or unrealistic low porosity (high $\phi$ ) values are given, and these values cannot be achieved at prototype scale using crawler cranes. When information concerning p or $\phi$ is available, it usually refers to an average value of the initial p or $\phi$ before wave attack. However, breakwater armours are always subject to Heterogeneous Packing (HeP), as described by Gómez-Martín and Medina (2014). Characterized by small displacements of armour units within the armour, HeP is sometimes referred to as armour "settlements” (e.g. Bakker et al., 2005). During test series in laboratory or service time in prototype, HeP leads to increased armour porosity near and above the MWL and a reduced porosity in the lower part of the armour. HeP without armour unit extraction results in a lower $\phi$ with fewer armour units per unit surface in the critical area near MWL, where $\phi$ also tends to be reduced by unit extraction. All types of armour units are affected by HeP due to the variation in porosity observed within the armour, although the effect is more intense in the case of high porosity armours and unit types with plane faces (e.g. cubes, Antifer cubes, etc.). Cube armours are highly sensitive to HeP, because of the face-to-face fitting tendency of cubes during construction and also in service time.

Armour porosity significantly influences energy dissipation, hydraulic stability, wave reflection, run-up and overtopping. Therefore, to properly describe breakwater armour stability, HeP should be taken into consideration, in addition to the average initial values of $\mathrm{p}$ or $\phi$. Conventional profiling and visual counting methods (see USACE, 1984, Medina et al., 1994, and Vidal et al., 2006) assume a constant void porosity in the armour and only take into account the unit extraction failure mode. The measurement of armour damage based on the relative number of displaced armour units (see Van der Meer, 1988) takes into account all unit 
extractions but only partially considers HeP. In this paper, the Virtual Net method, described by Gómez-Martín and Medina (2014), is used to measure armour damage to small-scale models. This method is appropriate to measure armour erosion in the critical area near MWL, simultaneously taking into account HeP and armour unit extraction. The Virtual Net method projects a virtual net over the orthogonal armour photograph after each wave run, and the armour is divided into horizontal strips of a constant width. The number of armour units, $\left\{\mathrm{N}_{\mathrm{i}}\right\}$, with the centre of gravity within each strip (i=1, $2 \ldots$ I) are counted after each wave run; the porosity of each strip i after wave attack, $\left\{\mathrm{p}_{\mathrm{i}}\right\}$, can be estimated using

$$
p_{i}=1-\frac{N_{i} D_{n}^{2}}{a b}=1-\frac{N_{i}}{m k}
$$

in which $\mathrm{i}$ is the strip index; $\mathrm{a}=\mathrm{mD}_{\mathrm{n}}$ and $\mathrm{b}=\mathrm{kD}$ are the strip width and length, respectively. The dimensionless armour damage in each strip after each wave run, $S_{i}$, can be calculated using

$$
S_{i}=m\left(1-\frac{1-p_{i}}{1-p_{i 0}}\right)=m\left(\frac{p_{i}-p_{i 0}}{1-p_{i 0}}\right)=m\left(1-\frac{\phi_{i}}{\phi_{i 0}}\right)
$$

in which $\mathrm{m}$ is the number of rows in each strip; $\mathrm{p}_{\mathrm{i} 0}$ and $\phi_{\mathrm{i} 0}$ are the initial armour porosity and packing density in strip $\mathrm{i}$; and $\mathrm{p}_{\mathrm{i}}$ and $\phi_{\mathrm{i}}$ are the armour porosity and packing density of strip $\mathrm{i}$ after the wave attack. Finally, the equivalent dimensionless armour damage, $\mathrm{S}_{\mathrm{e}}$, can be estimated integrating the positive values of $S_{i}$ along the slope.

$$
S_{e}=\sum_{i=1}^{I} S_{i} \quad \forall S_{i} \geq 0
$$

Small-scale models usually have a homogeneous initial armour porosity, $\mathrm{p}_{\mathrm{i} 0} \approx \mathrm{p}$; HeP after wave attack causes movement of the units in the armour to move, generating zones with heterogeneous porosity $\mathrm{p} \neq \mathrm{p}$ and $\mathrm{S}_{\mathrm{e}}>0$, although no armour unit is extracted from the armour. When cube units are extracted, HeP can be relevant with numerous face-to-face arrangements and the Virtual Net and Visual Counting methods provide significantly different armour damage measurements, as observed by Gómez-Martín and Medina (2014). If initial armour porosity p is very high, cube armours may have severe damage without armour unit extraction because of $\mathrm{HeP}$. $\mathrm{S}_{\mathrm{e}}$ is related to the conventional dimensionless damage, $\mathrm{S}$; however, it should be noted that the Visual Counting and other common methodologies to measure S may lead to significant differences for $S_{e}$, because conventional methods do not take into account the HeP failure mode but only armour unit extraction. 


\section{Experimental set-up and 2D-hydraulic stability tests}

To quantify the influence of armour porosity on the hydraulic stability of conventional cube armours, this study will analyse the armour damage observed from 2D hydraulic stability and overtopping tests based on the Punta Langosteira breakwater model ( $\cot \alpha=2.0$ ) during the construction phase. This study aims to analyse only the tests carried out at low water level (LWL) to minimize the influence of the relative crest freeboard $(\mathrm{Rc} / \mathrm{Dn}=4.8)$.

1/46 small-scale physical tests were carried out in the wind and wave test facility of the Laboratory of Ports and Coasts at the Universitat Politècnica de València (UPV). Wind was not considered a significant variable in this study. The UPV wave flume (30.0m long, $1.2 \mathrm{~m}$ wide and $1.2 \mathrm{~m}$ deep) has a piston-type wave paddle which generates regular and JONSWAP $(\gamma=3.3)$ random waves with AWACS active wave absorption. Water depth was $h(m)=0.87$ at the model and wavemaker area ( $\mathrm{h}=40 \mathrm{~m}$ at prototype scale)

Fig. 1 shows the cross section of the 1/46 scale model corresponding to the Punta Langosteira breakwater during the construction phase, namely, before building up the crownwall and placing the double-layer 150-tonne cube armour. During construction, the breakwater was protected with a conventional double-layer 15-tonne cube armour with a crest elevation $\mathrm{R}_{\mathrm{c}}(\mathrm{m})=+9.0$ above LWL. Table 1 lists the characteristics of the armour units, filter and core of the small-scale model. Armour units were placed on a filter layer $\left(\mathrm{D}_{\mathrm{n} 50}=1.78 \mathrm{~cm}\right)$ protecting the core $\left(\mathrm{D}_{\mathrm{n} 50}=0.675 \mathrm{~cm}\right)$. The results corresponding to 8 small-scale double-layer cube armour models with $35 \% \leq \mathrm{p} \leq 47 \%$ are analysed in this paper.

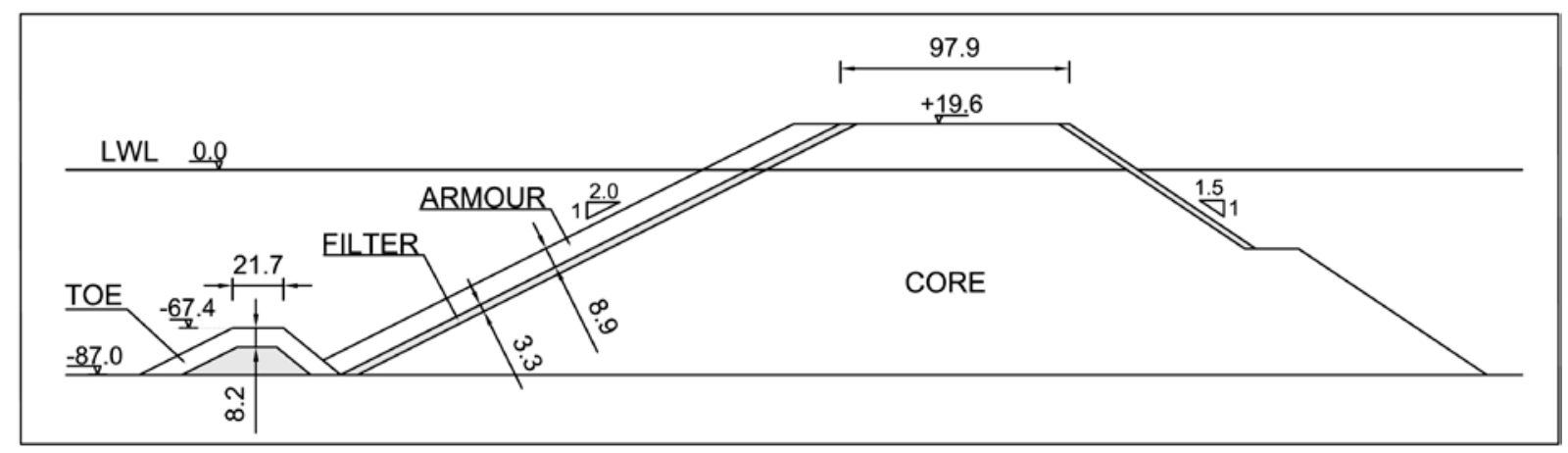

Figure 1. Punta Langosteria double-layer cube armoured breakwater cross section during the construction phase. 1/46 scale model (dimensions in $\mathrm{cm}$ ). 


\begin{tabular}{|c|c|c|c|}
\cline { 2 - 4 } \multicolumn{1}{c|}{} & \multicolumn{3}{c|}{ MODEL } \\
\cline { 2 - 4 } \multicolumn{1}{c|}{} & $\mathrm{D}_{\text {n50 }}(\mathrm{cm})$ & $\rho_{\mathrm{r}}\left(\mathrm{g} / \mathrm{cm}^{3}\right)$ & $\operatorname{mass}(\mathrm{g})$ \\
\hline Cube armour units & 4.08 & 2.30 & 156.2 \\
\hline Toe berm (rock) & 2.65 & 2.70 & 50.0 \\
\hline Filter layer (rock) & 1.78 & 2.70 & 15.3 \\
\hline Core & 0.67 & 2.70 & 0.83 \\
\hline
\end{tabular}

Table 1. Characteristics of materials used in the small-scale models.

In these experiments, the cube units do not have exact cube geometry, but rather a slightly squared frustro-pyramidal geometry, to facilitate the vertical demoulding, similar to the conventional cubes commonly used at prototype scale. Fig. 2 shows the cube unit cross section which is the 1/46 scale cube unit corresponding to the 15-tonne cube in the secondary armour of the Punta Langosteira breakwater.

The cube armour models were tested in non-breaking conditions; the design significant wave height $\mathrm{H}_{\mathrm{sd}}=12 \mathrm{~cm}$, corresponding to $\mathrm{K}_{\mathrm{D}}=6.0$ in Eq. 1, was used as reference for the hydraulic stability tests. The dimensionless crest freeboards were $\mathrm{R}_{\mathrm{c}} / \mathrm{H}_{\mathrm{sd}}=1.63$ and $\mathrm{R}_{\mathrm{c}} / \mathrm{D}_{\mathrm{n}}=4.8$ and the water depth to design significant wave height ratio was $\mathrm{h} / \mathrm{H}_{\mathrm{sd}}=87 / 12=7.2$.

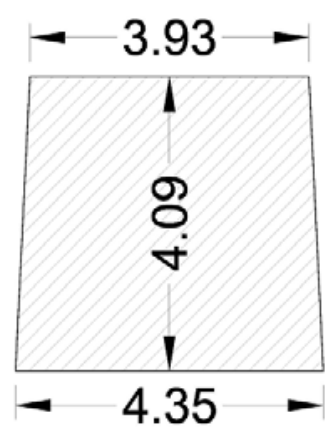

Figure 2. Cross section of the 1/46 scale cube units (dimensions in $\mathrm{cm}$ ).

Irregular wave tests were characterized by significant wave height and peak period, $H_{s}$ and $T_{p}$. Short series of regular waves were generated before initiating the tests series with irregular waves; in this study, the equivalence between regular and irregular wave characteristics was $\mathrm{H}=1.4 \mathrm{H}_{\mathrm{s}}$ and $\mathrm{T}=\mathrm{T}_{\mathrm{p}} / 1.2$. After constructing each model, a first orthogonal armour photograph was taken for reference, and runs of 50 regular waves were generated to consolidate the model. The first run with regular waves was selected below the design significant wave height $(\mathrm{H}=1.4 \times 8=11.2 \mathrm{~cm})$ and successive regular wave runs were generated increasing the wave height $\left(\mathrm{H}_{\mathrm{s}}=8 \mathrm{~cm}, 9 \mathrm{~cm}\right.$, etc.) until a significant movement was detected in the armour. Once the first movement was detected in the armour, the tests series with irregular waves were 
initiated. After each irregular wave run, $S_{e}$ was calculated using the Virtual Net method described in section 3 .

A total of forty-eight tests in eight test series were completed. The test series were characterized by an initial armour porosity (35\% $\leq \mathrm{p} \leq 47 \%$ corresponding to $1.30>\phi>1.06)$ and an approximately constant incident Iribarren number $3.0 \leq \operatorname{Ir}_{\mathrm{p}}=(1 / 2) /\left(2 \pi \mathrm{H}_{\mathrm{s}} / \mathrm{gT}_{\mathrm{p}}\right)^{20.5} \leq 6.3$ (corresponding to $0.028>\mathrm{s}_{\mathrm{op}}>0.006$ ). Three test series corresponded to low porosity armours $\left(\mathrm{p} \approx 37 \%\right.$ ) and $\operatorname{Ir}_{\mathrm{p}} \approx 3,4$ and 5 ; two test series corresponded to medium porosity armours $\left(\mathrm{p} \approx 41 \%\right.$ ) and $\mathrm{Ir}_{\mathrm{p}} \approx 3$ and 4 ; and three test series corresponded to high porosity armours $(\mathrm{p} \approx 46 \%)$ and $\mathrm{Ir}_{\mathrm{p}} \approx 4,5$ and 6 . One thousand random waves with JONSWAP $(\gamma=3.3)$ spectrum were generated in each irregular wave test. Significant wave height $\left(\mathrm{H}_{\mathrm{s}}\right)$ was increased progressively in steps, keeping approximately constant the wave steepness $\left(\mathrm{s}_{\mathrm{op}}=\mathrm{H}_{\mathrm{s}} / \mathrm{L}_{\mathrm{op}}\right.$ ) within the test series. Photographs perpendicular to the armour were taken after each test to calculate the armour damage $\mathrm{S}_{\mathrm{e}}$ corresponding to each $\mathrm{H}_{\mathrm{s}}$. The breakwater model was rebuilt after each test series, when the armour reached the initiation of destruction.

Water surface elevation was measured using capacity wave gauges at four points in the model area. The LASA-V method described by Figueres and Medina (2004) was used to estimate incident and reflected waves.

\section{Analysis of results}

In order to explicitly describe the influence of armour porosity on the hydraulic stability of the cube armours tested in the experiments described in section 4, the armour damage observations were analysed considering two different models which include the packing density as an explicative variable.

The stability number $\left(\mathrm{N}_{\mathrm{s}}=\mathrm{H}_{\mathrm{s}} / \Delta \mathrm{D}_{\mathrm{n}}\right)$ is usually related to armour damage through an explicit formula. According to Eq. 7 given by Burcharth and Liu (1992), a 1/3-power relationship between $\mathrm{N}_{\mathrm{s}}$ and $\mathrm{D}$ is valid for slender Dolos, while a 1/5-power relationship between $\mathrm{N}_{\mathrm{s}}$ and $\mathrm{S}$ is appropriate for massive rough quarrystone armours (see Van der Meer, 1988 and Medina et al., 1994). $\mathrm{N}_{\mathrm{s}}$ may be related as well to Iribarren's number or the wave steepness of incident waves; thus, Van der Meer (1999) proposed a negative 1/10-power relationship between Ns and wave steepness for cube armours valid for slope $\cot \alpha=1.5$. Finally, the literature review given in section 2.3 clearly indicates that $\mathrm{N}_{\mathrm{s}}$ is positively correlated to packing density, $\phi$. Thus, the following 4-parameter empirical formula was considered first, 


$$
N_{s}=\frac{H_{s}}{\Delta D_{n}}=a_{1} S_{e}^{a_{2}} \phi^{a_{3}} S_{o p}^{a_{4}}
$$

in which $\mathrm{N}_{\mathrm{s}}$ is the stability number; $\Delta=\left(\rho_{\mathrm{r}} / \rho_{\mathrm{w}}-1\right)$ is the relative submerged mass density; $D_{n}=\left(M / \rho_{r}\right)^{1 / 3}$ is the equivalent cube size or nominal diameter; $S_{e}$ is the equivalent armour damage calculated using Eqs. 8 to 10; $\phi=n(1-p)$ is the packing density given by Eq. 3 at the initiation of each test series; $\mathrm{s}_{\mathrm{op}}$ is the wave steepness, $\mathrm{s}_{\mathrm{op}}=\mathrm{H}_{\mathrm{s}} /\left(\mathrm{gT}_{\mathrm{p}}{ }^{2} / 2 \pi\right)$; and $\mathrm{a}_{\mathrm{i}}(\mathrm{i}=1$ to 4$)$ are four parameters to be estimated from the experimental data.

In addition to the formula given by Eq. 11, an alternative 5-parameter formula given by Eq. 12 based on Eq. 6 was also considered. Eq. 6 proposed by Van der Meer (1999) is not directly applicable to these data because $\cot \alpha=2.0$; however, Eq. 12 is a general formula corresponding to Eq. 6 with five free parameters which may be estimated from the test results,

$$
N_{s}=\frac{H_{s}}{\Delta D_{n}}=\left(b_{1}+b_{2} S_{e}^{b_{3}}+b_{4} \phi\right) s_{o p}^{b_{5}}
$$

in which the notation is the same as that used in Eq. 11 and $b_{i}(i=1$ to 5) are five parameters to be estimated from the experimental data.

\subsection{Best fitting parameters}

The eight cube armoured models and test series, described in section 4, provided 48 armour damage observations in the range $1.0 \leq \mathrm{S}_{\mathrm{e}} \leq 13.5$ (from initiation of damage to initiation of destruction), with $0.006 \leq \mathrm{s}_{\mathrm{op}} \leq 0.028$ and $1.06 \leq \phi \leq 1.30$. The mean squared error to variance ratio (MSE/Var) was used to compare the lack of fit of alternative formulae to experimental observations,

$$
\frac{M S E}{\operatorname{Var}}=\frac{\sum_{j=1}^{J} \frac{\left(N_{s e j}-N_{s o j}\right)^{2}}{J}}{\operatorname{Var}}
$$

in which $\mathrm{N}_{\text {soj }}$ and $\mathrm{N}_{\text {sej }}$ are the observed and estimated stability numbers, respectively, of test $\mathrm{j}$ $(\mathrm{j}=1$ to $\mathrm{J})$; $\mathrm{J}$ is the number of tests analysed; and $\operatorname{Var}=\operatorname{Var}\left(\mathrm{N}_{\mathrm{soj}}\right)$ is the variance of the $\mathrm{J}=48$ observed stability numbers. When the number of data is much larger than the number of parameters to be fitted, MSE/Var is a good estimator of the part of the variance of the observations not explained by the estimation formula.

Taking the logarithms from both sides of the Eq. 11, $a_{i}$ (i=1 to 4) parameters can be easily estimated by linear regression. Three explicative variables ( $S_{e}, \phi$ and $S_{o p}$ ) were found to be significant variables to explain the observed $\mathrm{N}_{\mathrm{s}}$, which has a significance level of $5 \%$. The 
linear regression analysis provided the central estimations and confidence intervals of the four parameters, and the logarithms are reversed to calculate $a_{i}(i=1$ to 4 ) in Eq. 11. The central estimations were $\mathrm{a}_{1}=+0.733, \mathrm{a}_{2}=+0.236, \mathrm{a}_{3}=+1.572$ and $\mathrm{a}_{4}=-0.152$ which gave $\mathrm{a}$ MSE/Var=23.4\%. The coefficient of variation was approximately $20 \%$ for $\mathrm{a}_{1}$ and $\mathrm{a}_{4}$, and $13 \%$ for $\mathrm{a}_{2}$ and $\mathrm{a}_{3}$; therefore, the experimental data do not support these estimations with more than two significant figures. The following formula using parameters with two significant figures has a MSE/Var=23.5\%

$$
N_{s}=\frac{H_{s}}{\Delta D_{n}}=0.74 S_{e}^{0.24} \phi^{1.6} S_{o p}^{-0.15}
$$

in which $\cot \alpha=2.0,1.0 \leq \mathrm{S}_{\mathrm{e}} \leq 13.5,1.06 \leq \phi \leq 1.30,0.006 \leq \mathrm{S}_{\mathrm{op}} \leq 0.028$ (3.0 $\leq \operatorname{Ir}_{\mathrm{p}} \leq 6.3$ ). In order to assess the uncertainty associated with the use of Eq. 14 and to estimate the stability number of double-layer cube armours with $\cot \alpha=2.0$, it is convenient to calculate the final prediction error (FPE). The FPE takes into account not only MSE, but also the number of test cases used in the estimation and the number of free parameters used in the formula. According to Barron (1984), the final prediction error is $\mathrm{FPE}=\mathrm{MSE}([\mathrm{J}+\mathrm{Q}] /[\mathrm{J}-\mathrm{Q}])$; in this case, $\mathrm{J}=48$ and $\mathrm{Q}=4$. Assuming a Gaussian error distribution, the $90 \%$ confidence interval associated to the estimations given by Eq. 14 is $\mathrm{Ns} \pm 1.65(\mathrm{FPE})^{0.5}=\mathrm{Ns} \pm 0.37$. Fig. 3 compares the $\mathrm{N}_{\mathrm{s}}$ estimations using Eq. 14 and the measured stability numbers.

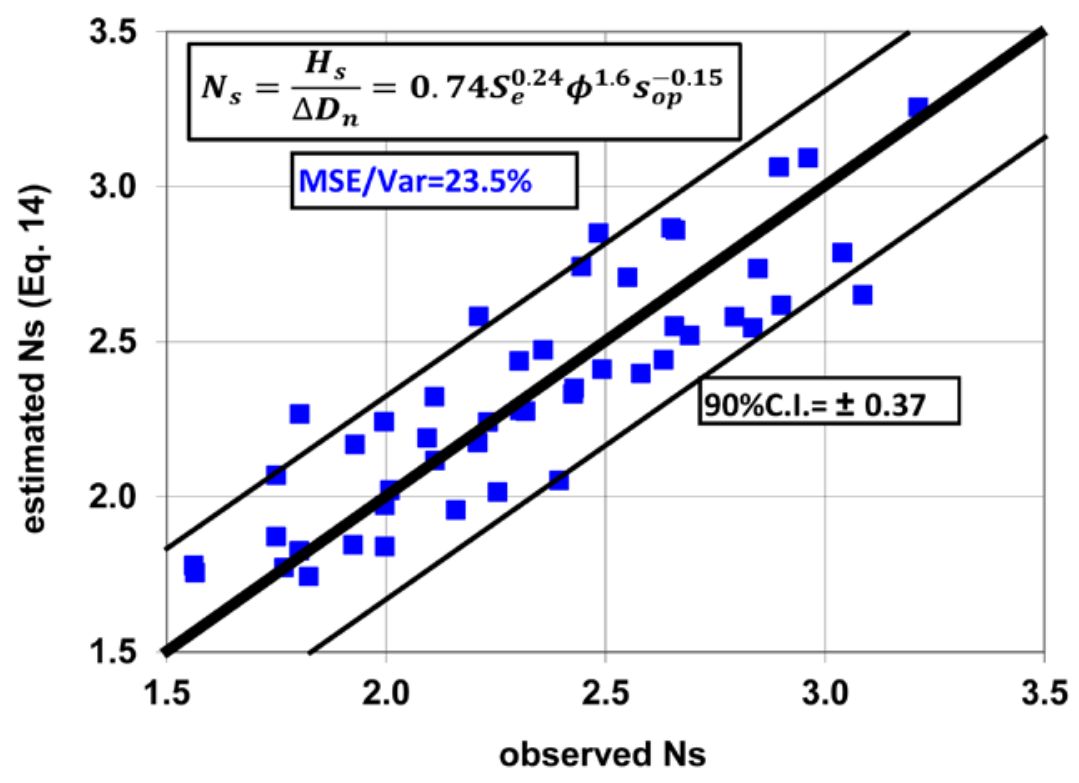

Figure 3. Comparison of observed $N_{s}$ and estimation given by Eq. 14.

The parameters $b_{i}(i=1 \mathrm{t}$ o5) in Eq. 12 which minimize MSE/Var result in the following 
formula

$$
N_{s}=\frac{H_{s}}{\Delta D_{n}}=\left(0.34 S_{e}^{0.5}-1.2+1.8 \phi\right) s_{o p}^{-0.1}
$$

with MSE/Var=24.5\%. The same methodology described above is used to quantify the uncertainty of the estimations given by Eq. 15. Assuming a Gaussian error distribution, the $90 \%$ confidence interval associated to the estimations given by Eq. 15 is Ns $\pm 1.65(\mathrm{FPE})^{0.5}=$ Ns \pm 0.38. Fig. 4 compares the $\mathrm{N}_{\mathrm{s}}$ estimations using Eq. 15 and the measured stability numbers.

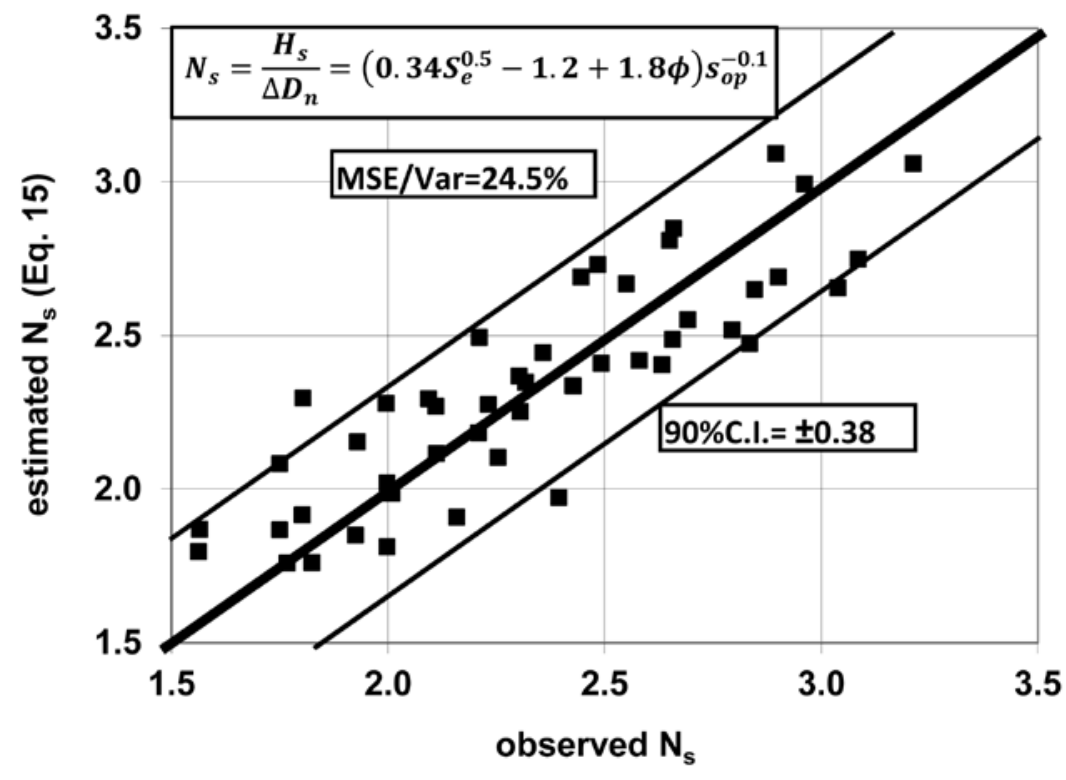

Figure 4. Comparison of observed $N_{s}$ and estimation given by Eq. 15.

Eq. 14 appears to be slightly better than Eq. 15 because confidence intervals are 4\% narrower; Eq. 14 has lower MSE/Var and fewer parameters. However, the difference in performance between Eq. 14 and 15 is too small to justify rejecting Eq. 15.

For the 48 tests described above, and considering Eq. 15 to estimate Eq. 14, a very small MSE/Var=2.4\% is obtained. This low MSE/Var indicates that estimations given by Eq. 14 and 15 are very close each other in the range of the data: $1.0 \leq \mathrm{S}_{\mathrm{e}} \leq 13.5,1.06 \leq \phi \leq 1.30$, $0.006 \leq \mathrm{s}_{\mathrm{op}} \leq 0.028$. Fig. 5 compares the estimations provided by Eq. 14 and 15 corresponding to the experimental $\mathrm{N}_{\mathrm{s}}$ observations. Although Eq. 14 looks very different from Eq. 15, the two formulae are almost equivalent for practical applications in the range of the experimental data. 


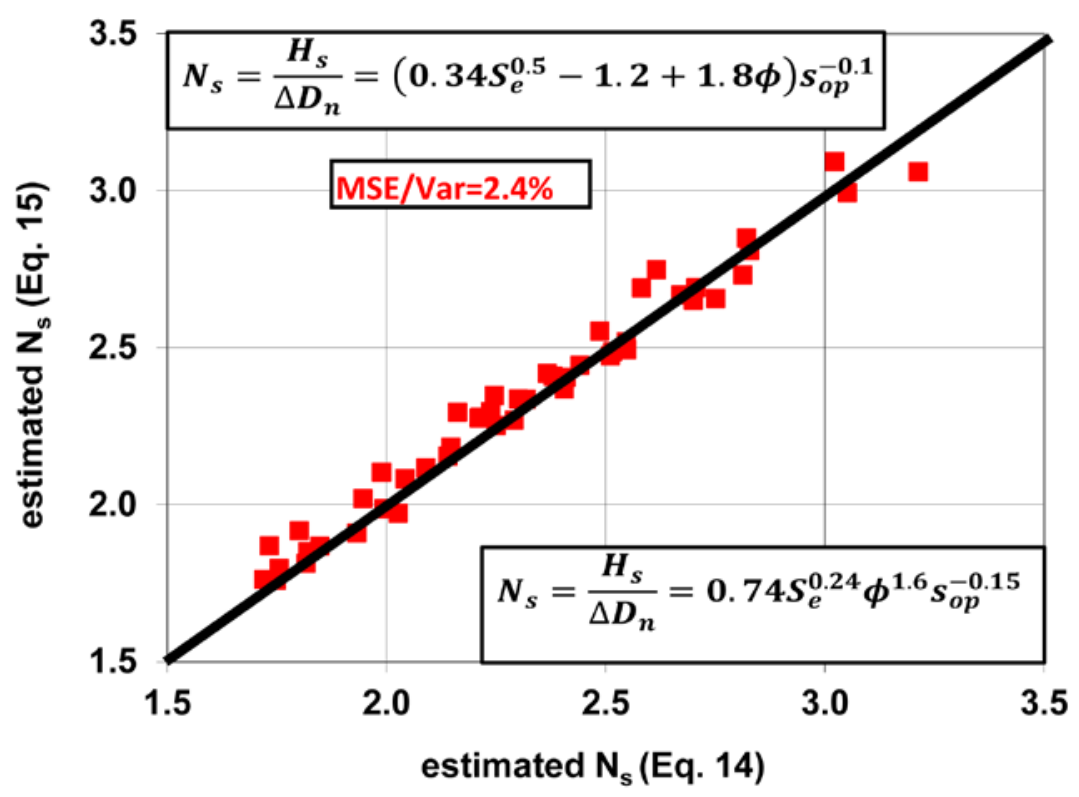

Figure 5. Comparison of estimated $N_{s}$ by Eq. 14 and Eq. 15.

\subsection{Model generalization}

The methodology used to build up the parametric model described by Eq. 14 is applied in this section to calculate a formula to be applied within the broader range $1.5 \leq \cot \alpha \leq 2.0$. In addition to the data obtained from the experiments described in section 4, new data from 66 hydraulic stability tests of double-layer cube armours with $\cot \alpha=1.5$ and initial armour porosity $\mathrm{p}=37 \%(\phi=1.26)$ are considered for further analysis.

The new data are taken from the experiments described by Gómez-Martín and Medina (2014) using the same methodology explained previously, but selecting only the data in the application range of Eq. 14: $1.0 \leq \mathrm{S}_{\mathrm{e}} \leq 13.5,1.06 \leq \phi \leq 1.30,3.0 \leq \operatorname{Ir}_{\mathrm{p}} \leq 6.3\left(0.006 \leq \mathrm{s}_{\mathrm{op}} \leq 0.028\right)$. The physical experiments were also carried out in the UPV wave flume described in section 4; Fig. 6 shows the cross section of the model with slope $\cot \alpha=1.5$. The cube units used in this model were regular cubes with $\mathrm{D}_{\mathrm{n}}(\mathrm{cm})=4.00$ and $\rho_{\mathrm{r}}\left(\mathrm{g} / \mathrm{cm}^{3}\right)=2.18$, slightly different than those used in the model described by Fig. 1. The model was tested in non-breaking and nonovertopping conditions with a dimensionless crest freeboard $R_{c} / D_{n}=10.0$, higher than $R_{C} / D_{n}=4.8$ corresponding to Fig. 1 . There was no toe berm in this model (see Fig. 6) and the water depth to design significant wave height ratio, $h / \mathrm{H}_{\mathrm{sd}}=50 / 9.8=5.1$, was lower than $\mathrm{h} / \mathrm{H}_{\mathrm{sd}}=87 / 12.1=7.2$ in Fig. 1. 


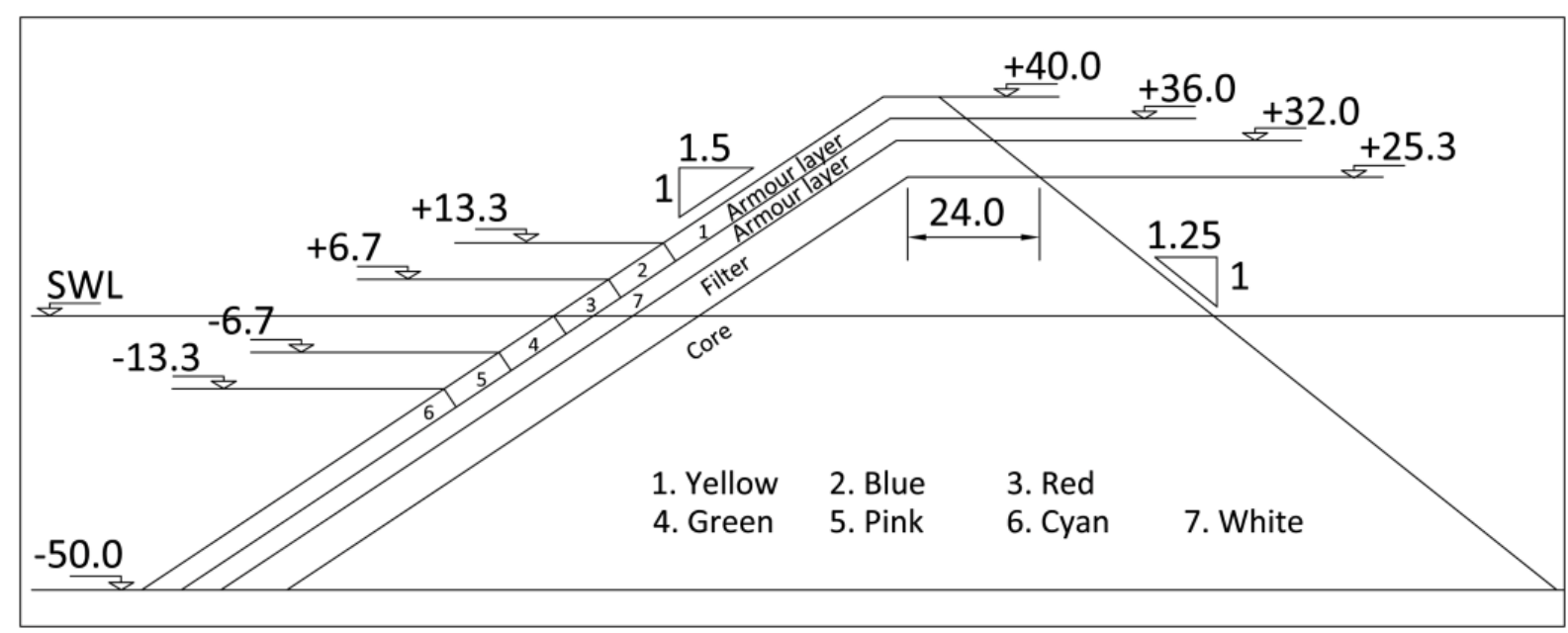

Figure 6. Cube armoured breakwater cross section (dimensions in $\mathrm{cm}$ ).

Despite the differences between the structural characteristics of cross sections described by Figs. 1 and 6, the observed armour damage to both structures was used to obtain a formula which aims to be valid for a broad range of applications within $1.5 \leq \cot \alpha \leq 2.0$ slope. The methodology is the same as that used in the previous section to obtain Eq. 14. The 48 test data corresponding to eight test series with $\cot \alpha=2.0$ and the additional 66 test data corresponding to ten test series with $\cot \alpha=1.5$ were used to estimate the parameters. $\operatorname{Ir}_{\mathrm{p}}=[\tan \alpha] /\left[2 \pi \mathrm{H}_{\mathrm{s}} / \mathrm{gT}_{\mathrm{p}}{ }^{2}\right]^{0.5}$ was considered an explicative variable instead of wave steepness, $\mathrm{s}_{\mathrm{op}}=\mathrm{H}_{\mathrm{s}} /\left[\mathrm{gT}_{\mathrm{p}}{ }^{2} / 2 \pi\right]$, because Iribarren's number, $\operatorname{Ir}_{\mathrm{p}}=[\tan \alpha] /\left[\mathrm{s}_{\mathrm{op}}\right]^{0.5}$, controls the breaking process on the armour slope and contains the information about wave steepness. Further, the armour slope cot $\alpha$ was included as an additional explicative variable.

The linear regression provided the following significant variables: $S_{e}, \phi$ and $\cot \alpha$. With a level of significance of $5 \%$, both $\operatorname{Ir}_{\mathrm{p}}$ and $\mathrm{s}_{\mathrm{op}}$ were rejected as significant explicative variables. Thus, Eq. 16, having MSE/Var=28.9\%, provides a reasonable estimation as to how armour porosity affects hydraulic stability, valid for $1.5 \leq \cot \alpha \leq 2.0$ in the range $1.0 \leq \mathrm{S}_{\mathrm{e}} \leq 13.5$, $1.06 \leq \phi \leq 1.30$.

$$
N_{s}=\frac{H_{s}}{\Delta D_{n}}=1.31 S_{e}^{0.21} \phi^{1.2}(\cot \alpha)^{0.20}
$$

The same methodology described previously was used here to quantify the uncertainty of the estimations given by Eq. 16 . The $90 \%$ confidence interval associated to the estimations given by Eq. 16 is $\mathrm{Ns} \pm 1.65(\mathrm{FPE})^{0.5}=\mathrm{Ns} \pm 0.39$. Fig. 7 compares the $\mathrm{N}_{\mathrm{s}}$ estimations using Eq. 16 and the measured stability numbers; the 48 test data corresponding to Fig. $1 \quad(\cot \alpha=2)$ are represented by squares and the 66 test data corresponding to Fig. $5(\cot \alpha=1.5)$ are represented 
by triangles.

In Eq. 16, the exponent of the packing density was 1.2, lower than the 1.6 obtained in Eq. 14; however, due to the uncertainty of this exponent in Eq. 14, the exponent 1.2 falls in the acceptability range with a 5\% significance level.

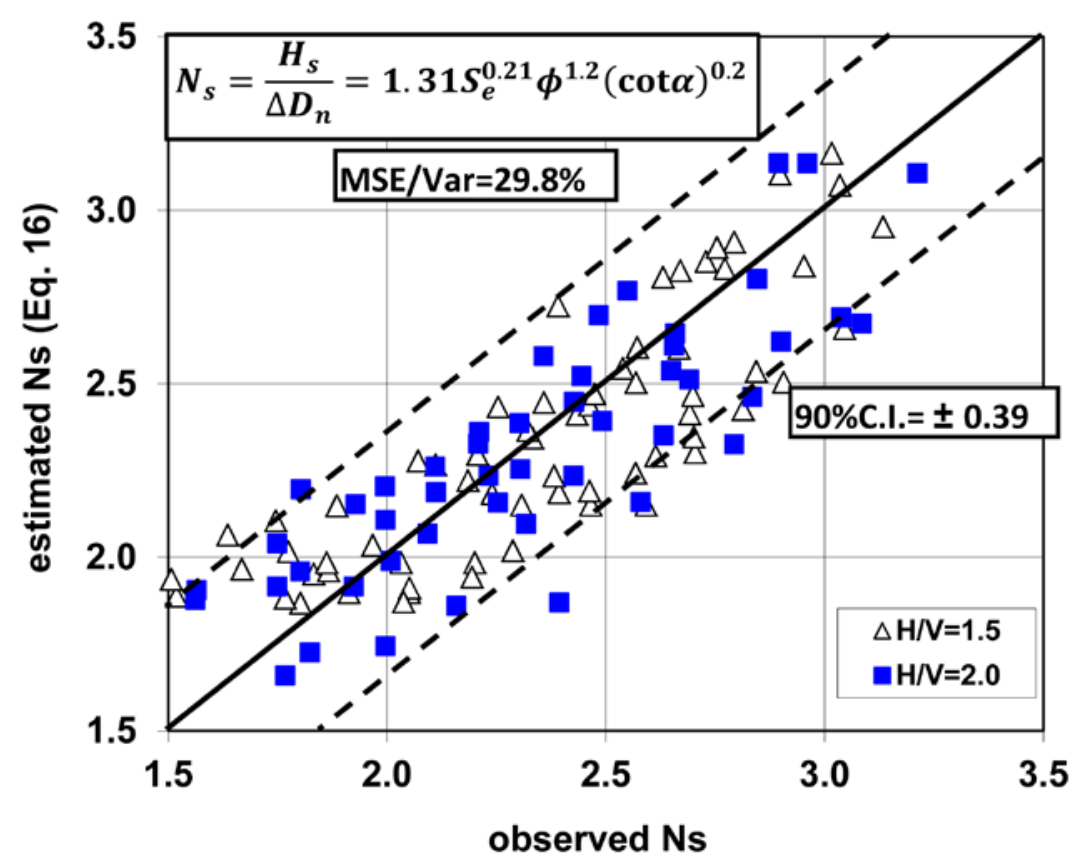

Figure 7. Comparison of observed $N_{s}$ and Eq. 16 estimations.

\subsection{Discussion regarding concrete consumption}

During the preliminary design phase, design storm and construction site conditions are usually given. In general terms, concrete consumption is approximately proportional to $\phi \mathrm{D}_{\mathrm{n}} / \operatorname{sen} \alpha$; if the variables $\mathrm{H}_{\mathrm{s}}, \mathrm{S}_{\mathrm{e}}$ and $\Delta$ are fixed in Eq. 16, the concrete consumption is directly proportional to

$$
\frac{\phi D_{n}}{\operatorname{sen} \alpha}=\frac{c}{\phi^{0.2} \operatorname{sen} \alpha(\cot \alpha)^{0.2}}
$$

in which $D_{n}$ is the equivalent cube size or nominal diameter; $\phi$ is the packing density $(1.06 \leq \phi \leq 1.30) ; \alpha$ is the slope angle $(1.5 \leq \cot \alpha \leq 2.0)$; and c is a constant which depends on the design storm and construction site conditions. According to Eq. 17, for double-layer randomly-placed cube armours, concrete consumption decreases if both packing density and slope angle increase. Considering Eqs. 16 and 17, if the armour slope increases from $\cot \alpha$ $=2.0$ to $\cot \alpha=1.5$, armour unit mass increases $19 \%$ but concrete consumption decreases $15 \%$.

Taking into account Eqs. 16 and 17, if packing density increases from the recommended $\phi=1.17(\mathrm{p}=41.5 \%)$ to $\phi=1.26(\mathrm{p}=37 \%)$, concrete consumption decreases $1.5 \%$ and armour 
unit mass decreases 23\%. There are clear advantages to reducing armour porosity; however, random placement of cubes at prototype scale is more difficult if armour porosity is lower. If placement grids, crawler cranes and pressure clamps are used, random placement of cubes is not feasible below p=35\% (see Medina et al., 2010).

Armour porosity should be determined during the preliminary design phase, considering the equipment and control system to be used during the construction phase. Armour porosity should be controlled and reported when small-scale tests are carried out to validate the preliminary design. Finally, placement densities should be reported at prototype scale in order to assess the real packing density and armour porosity of the breakwater. If the packing density at prototype scale is lower or higher than that considered in the small-scale tests, Eq. 16 may be used to improve the estimation of the prototype failure function from the smallscale experiments.

\section{Conclusions}

A review of the literature concerning different armour units consistently indicates packing density significantly affects the hydraulic stability of single- and double-layer armours of mound breakwaters. A lower-than-recommended packing density reduces the armour hydraulic stability. Forty-eight hydraulic stability tests in eight test series of double-layer cube armours with slope $\cot \alpha=2.0$ and different packing densities $(1.06 \leq \phi \leq 1.30)$ were carried out in the UPV wave flume. The tests corresponded to a 1/46-scale model of the Punta Langosteira breakwater during the construction phase; it has a very deep, non-breaking, minor overtopping cross-section with a very large toe berm. The Virtual Net method was used to measure armour damage, considering both armour unit extraction and movements within the armour (HeP). The stability number was found to be dependent on the damage level, $S_{e}$, wave steepness, $\mathrm{S}_{\mathrm{op}}$, and packing density, $\phi$.

An additional 66 hydraulic stability tests in ten test series of double-layer cube armours with slope $\cot \alpha=1.5$ and constant armour porosity $\mathrm{p}=37 \%(\phi=1.26)$ were also analysed using the same methodology. These additional tests corresponded to non-breaking and non-overtopping cross-section without toe berm.

For all the 114 hydraulic stability tests with permeable core and slopes $\cot \alpha=1.5$ and 2.0, the stability number was found to be dependent on the damage level, $\mathrm{S}_{\mathrm{e}}$, packing density, $\phi$, and slope, $\cot \alpha$; Iribarren's number and wave steepness were rejected as significant explicative variables, with a level of significance of 5\%. Eq. 16 provided an estimation of the stability 
number valid for $1.5 \leq \cot \alpha \leq 2.0$ with a $90 \%$ confidence interval: Ns \pm 0.39 . The stability number showed a 1.2-power relationship with packing density; therefore, the risk of failure increases significantly when the packing density at prototype is reduced to below design value.

In general terms, concrete consumption in the armour layer is approximately proportional to $\phi \mathrm{D}_{\mathrm{n}} / \mathrm{sen} \alpha$. Considering Eq. 16 in the preliminary design phase, concrete consumption decreases if the packing density and slope angle increase. However, random placement of cubes below MWL is not feasible for $\mathrm{p} \leq 35 \%$, when constructing with placement grids, crawler cranes and pressure clamps. For better risk assessment, packing density should be explicitly reported in small-scale hydraulic stability tests and design packing density must be controlled and measured at prototype scale.

\section{Acknowledgements}

The authors are grateful for financial support from the Spanish Ministerio de Economía y Competitividad and FEDER (Grant BIA2012-33967) and CDTI (CUBIPOD and CLIOMAR Projects). The second author was funded through the FPU program (Formación del Profesorado Universitario) by the Spanish Ministerio de Educación, Cultura y Deporte. The authors also thank Debra Westall for revising the manuscript.

\section{References}

Bakker, P., Klabbers, M., Muttray, M., Van den Berge, A., 2005. Hydraulic performance of Xbloc ${ }^{\circledR}$ armour units. $1^{\text {st }}$ Int. Conf. on Coastal Zone Management and Engineering in the Middle East. Dubai, November 2005.

Barron, A., 1984. Predicted squared error: A criterion for automatic model selection. In S. Farlow (ed.), Self-Organizing Methods in Modelling, 87-103, Marcel Dekker, New York. Burcharth, H.F., Liu, Z., 1992. Design of Dolos armour units. Proc. $23^{\text {rd }}$ Int. Conf. on Coastal Engineering, ASCE, 1053-1066.

Burcharth, H.F., Christensen, M., Jensen, T., Frigaard, P., 1998. Influence of core permeability on Accropode stability. Proc. Conf. on Coastlines, Structures and Breakwaters, ICE, London, Thomas Telford, 34-45+304-306.

Carver, R.D., Davidson, D.D., 1978. Dolos-armored breakwaters: Special considerations. Proc. $16^{\text {th }}$ Int. Conf. on Coastal Engineering, ASCE, 2263-2284. 
CIRIA, CUR, CETMEF, 2007. The Rock Manual. The use of rock in hydraulic engineering ( $2^{\text {nd }}$ edition). C683, CIRIA, London.

CLI, 2012. Sustainable protection for breakwaters. ACCROPODE ${ }^{\mathrm{TM}}$ and CORE-LOC ${ }^{\mathrm{TM}}$. http://www.concretelayer.com/ (Consulted 18/10/2012).

De Jong, W., Verhagen, H.J., Olthof, J., 2004. Experimental research on the stability of armour and secondary layers in a single layered tetrapod breakwater. Proc. $29^{\text {th }}$ Int. Conf. on Coastal Engineering, World Scientific, Singapore, 3520-3529.

DMC, 2011. Guidelines for Xbloc Concept design. Delta Marine Consultants, Sep. 2011.

Dupray, S., Roberts, J., 2009. Review of the use of concrete in the manufacture of concrete armour units. Proc. of Coasts, Marine Structures and Breakwaters 2009, Institution of Civil Engineers (ICE), Thomas Telford Ltd., Vol. 1, 245-259.

Figueres, M., Medina, J.R., 2004. Estimation of incident and reflected waves using a fully non-linear wave model. Proc. $29^{\text {th }}$ Int. Conf. on Coastal Engineering, World Scientific, Singapore, 594-603.

Frens, A.B., 2007. The impact of placement technique on Antifer-block stability. M.Sc. thesis, Delft University of Technology, The Netherlands.

Gómez-Martín, M.E., and Medina, J.R., 2014. Heterogeneous packing and hydraulic stability of cube and Cubipod armor units. Journal of Waterway, Port, Coastal and Ocean Engineering, ASCE, 140(1): 100-108.

Gürer, S., Çevik, E., Yüksel, Y., Günbak, A.R., 2005. Stability of Tetrapod breakwaters for different placing methods. Journal of Coastal Research, 21(3): 464-471.

Hald, T., Torum, A., and Holm-Karlsen, T., 1998. Design of rock armoured single layer rubble mound breakwaters. Proc. $26^{\text {th }}$ Int. Conf. on Coastal Engineering, ASCE, 18001813.

Holtzhausen, A.H., Zwamborn, J.A., 1991. Stability of Accropode ${ }^{\circledR}$ and comparison with dolosse. Coastal Engineering, 15(1-2): 59-86.

Holtzhausen, A.H., 1998. The first Core-Loc breakwater. Proc. $26^{\text {th }}$ Int. Conf. on Coastal Engineering, ASCE, 1871-1883.

Hudson, R.Y., 1959. Laboratory investigation of rubble-mound breakwaters. Journal of the Waterways and Harbors Division, ASCE, 85(WW3): 93-121.

Jensen, O.J., 2013. Safety of Breakwater Armour Layers with Special Focus on Monolayer Armour Units. Proc. of Coasts, Marine Structures and Breakwaters 2013, Institution of Civil Engineers (in press). 
Latham, J.P., Newberr, S., Mannion, M., Simm, J., Stewart, T., 2002. The void porosity of rock armour in coastal structures. Water and Maritime Engineering, 154(3): 189-198.

Latham, J.P., Anastasaki, E., Xiang, J., 2013. New modelling and analysis methods for concrete armour unit systems using FEMDEM. Coastal Engineering, 77: 151-166.

Medina, J.R., Hudspeth, R.T., Fassardi, C., 1994. Breakwater Armour Damage due to Wave Groups. Journal of Waterway, Port, Coastal, and Ocean Engineering, 120(2): 179-198.

Medina, J.R., Gómez-Martín, M.E., Corredor, A., 2010. Influence of armour unit placement on armour porosity and hydraulic stability. Proc. $32^{\text {nd }}$ Int. Conf. on Coastal Engineering, ASCE, 1(32), structures.41. doi:10.9753/icce.v32.structures.41.

Melby, J.A., Turk, G.F., 1994. CORE-LOC: Optimized concrete armor units. PIANC Bulletin, $\mathrm{N}^{\circ}$ 87, 5-20.

Mouquet, A., 2009. Armour unit placement and positioning in 3D real time. Proc. Coasts, Marine Structures and Breakwaters 2009, Institution of Civil Engineers (ICE), Thomas Telford Ltd., Vol. 1, 437-447 + 461-462.

Paulsen, J., Wareing, A., 2009. An overview of the construction of the Core-loc ${ }^{\mathrm{TM}}$ armoured breakwater at Newbiggin-by-the-Sea, Northumberland. Proc. Coasts, Marine Structures and Breakwaters 2009, Institution of Civil Engineers (ICE), Thomas Telford Ltd., Vol. 1, 412-424+460-461.

U.S. Army Corps of Engineers (USACE), 1984. Shore protection manual. U.S. Army Engineer Waterways Experiment Station, Coastal and Hydraulics Laboratory, Vicksburg, MS.

Van Buchem, R.V., 2009. Stability of a single top layer of cubes. M.Sc. thesis, Delft University of Technology, The Netherlands.

Van der Meer, J.W., 1988. Stability of Cubes, Tetrapodes and Accropodes. Proc. Coasts, Marine Structures and Breakwaters 1988, Institution of Civil Engineers (ICE), Thomas Telford Ltd., 71-80.

Van der Meer, J.W., 1999. Design of concrete armour layers. Proc., $3^{\text {rd }}$ Coastal Structures Int. Conf. A.A. Balkema, Rotterdam, 213-221.

Van Gelderen, P., Auld, S., 2009. Innovative technique for single layer armour unit placement. Proc. Coasts, Marine Structures and Breakwaters 2009, Institution of Civil Engineers (ICE), Thomas Telford Ltd., Vol. 1, 425-436+461.

Van Gent, M.R.A., Plate, S.E., Spaan, G.B.H., Van der Meer, J.W., d’Angremond, K., 1999. Single-layer rubble mound breakwaters. Proc., $3^{\text {rd }}$ Int. Conf. on Coastal Structures, A.A. Balkema, Rotterdam, 231-239. 
Vandenbosch, A., Angremond, K.D., Verhagen, H.J., Olthof, J., 2002. Influence of the density of placement on the stability of armour layers on breakwaters. Proc., $28^{\text {th }}$ Int. Conf. on Coastal Engineering, World Scientific, Singapore, 1537-1549.

Vidal, C., Medina, R., Lomonaco, P., 2006. Wave height parameter for damage description of rubble-mound breakwaters. Coastal Engineering, 53(9): 711-722.

Vincent, G., Tourmen, L., Gonzalo-Vara, J., 1989. Diques marítimos. Revista de Obras Públicas, Sep. 1989, 657-667 (in Spanish).

Yagci, O., Kapdasli, S., 2003. Alternative placement technique for Antifer blocks used on breakwaters. Ocean Engineering, 30(11): 1433-1451.

Yagci, O., Kapdasli, S., Cigizoglu, H.K. 2004. The stability of the Antifer units used on breakwaters in case of irregular placement. Ocean Engineering, 31(8): 1111-1127.

Zwamborn, J.A., 1978. Dolos packing density and effect of relative block density. Proc. $17^{\text {th }}$ Int. Conf. on Coastal Engineering, ASCE, 2285-2303. 


\section{LIST OF TABLES}

Table 1. Characteristics of materials used in the small-scale models.

\section{LIST OF FIGURES}

Figure 1. Punta Langosteria cube armoured breakwater cross section during construction. 1/46 scale model (dimensions in $\mathrm{cm}$ ).

Figure 2. Cross section of the 1/46 scale cube units (dimensions in $\mathrm{cm}$ ).

Figure 3. Comparison of observed $N_{s}$ and Eq. 14 estimation (double-layer cube armour).

Figure 4. Comparison of observed $N_{s}$ and Eq. 15 estimation (double-layer cube armour).

Figure 5. Comparison of estimated $N_{s}$ by Eq. 14 and Eq. 15.

Figure 6. Cube armoured breakwater cross section (dimensions in $\mathrm{cm}$ ).

Figure 7. Comparison of observed $N_{s}$ and Eq. 16 estimations. 